\title{
Rancang Bangun Game Edukasi Perjalanan Dang Hyang Nirartha di Bali
}

\author{
Ni Luh Candra Darmayanti, I Ketut Adi Purnawan, Putu Wira Buana \\ Program Studi Teknologi Informasi Universitas Udayana \\ Bukit Jimbaran, Bali, Indonesia, telp. (0361) 701806 \\ e-mail : candradmy@gmail.com, dosenadi@yahoo.com, wbhuana@it.unud.ac.id
}

\begin{abstract}
Abstrak
Dang Hyang Nirartha merupakan seorang pemuka agama yang tersohor. Dang Hyang Nirartha memberikan banyak perubahan kepada Nusantara salah satunya Pulau Bali. Dang Hyang Nirartha memberikan banyak perubahan dalam penyesuaian konsep Agama Hindu dengan budaya yang ada di Bali. Game Edukasi Perjalanan Dang Hyang Nirartha di Bali dikembangkan bertujuan untuk mengedukasi masyarakat terkait perjalanan Dang Hyang Nirartha di Bali, mengingat pentingnya peran Dang Hyang Nirartha bagi masyarakat Bali. Game Edukasi Perjalanan Dang Hyang Nirartha di Bali dikembangkan menggunakan metode accelerometer, sehingga nantinya user cukup memiringkan smartphone untuk menggerakkan karakter ke arah atas, bawah, kiri dan kanan untuk menghindari musuh serta dapat menyelesaikan permainan. Game yang dihasilkan mampu menyampaikan pembelajaran tentang perjalanan Dang Hyang Nirartha di Bali melalui informasi yang ditampilkan pada setiap stage dan gameplay yang menggambarkan kondisi perjalanan Dang Hyang Nirartha di Bali.
\end{abstract}

Kata Kunci: Game Edukasi, Mobile Game, Dang Hyang Nirartha, Android, Accelerometer, Budaya

\begin{abstract}
Dang Hyang Nirartha is a prominent Hindu religious leader in the Indonesian archipelago. Dang Hyang Nirartha gave many changes to the archipelago of one of the island of Bali. Dang Hyang Nirartha provides many changes in the adaptation of the Hindu Religion concept to the existing culture in Bali. Dang Hyang Nirartha's Travel Educational Game in Bali was developed to educate people about Dang Hyang Nirartha's journey in Bali, given the importance of Dang Hyang Nirartha's role for the people of Bali. Dang Hyang Nirartha's Travel Educational Game in Bali was developed using the accelerometer method, so that later the user simply tilts the smartphone to move the character up, down, left and right to avoid the enemy and can finish the game. The resulting game is able to convey the learning about Dang Hyang Nirartha's journey in Bali through the information displayed on every stage and gameplay that describes Dang Hyang Nirartha's travel conditions in Bali.
\end{abstract}

Keywords: Game Edukasi, Mobile Game, Dang Hyang Nirartha, Android, Accelerometer, Culture

\section{Pendahuluan}

Dang Hyang Nirartha merupakan seorang pemuka agama yang tersohor. Dang Hyang Nirartha memberikan banyak perubahan kepada Nusantara salah satunya Pulau Bali. Sejarah Dang Hyang Nirartha di Bali dimulai ketika Dang Hyang Nirartha menyeberangi Selat Bali dari Pulau Jawa. Kabupaten Jembrana merupakan tempat pertama yang didatangi Dang Hyang Nirartha di Bali hingga mencapai moksa di Pura Uluwatu Kabupaten Badung [1].

Penelitian sebelumnya yang dilakukan oleh Nelly Indriani Widiastuti dan Irwan Setiawan dari jurnal "Membangun Game Edukasi Sejarah Walisongo", Tahun 2012 menjelaskan tentang game Sejarah Walisongo dimainkan dengan mendapatkan sembilan foto dari tokoh Walisongo dan mengalahkan tiga bos zombie atau musuh dalam game. Game Edukasi sejarah Walisongo dapat menarik minat siswa siswi belajar sejarah Walisongo dan dapat digunakan sebagai media alternatif pembelajaran untuk membantu dalam proses belajar, khususnya mengenai pelajaran Sejarah Walisongo [2]. Penelitian berikutnya yang mendukung pelestarian budaya Bali yaitu penelitian oleh I Dewa Made Yuda Aditya Putra yang berjudul Rancang Bangun Game Tapel 
Bali Berbasis Android pada Tahun 2015. Penelitian bertujuan untuk melestarikan Budaya Bali khususnya mengenalkan Tapel Bali yang sudah jarang ditemui ke masyarakat luas. Game Tapel Bali memiliki 12 level permainan, setiap level yang berhasil diselesaikan menampilkan informasi tentang Tapel Bali [3]. Penelitian serupa oleh Ni Putu Sinria Franza yang berjudul Application of Basic Balinese Dance using Augmented Reality on Android pada Tahun 2016, mengkombinasikan aplikasi berbasis Android dengan teknologi Augmented Reality yang menjadi aplikasi media pembelajaran untuk mempelajari gerakan dasar Tari Bali. Aplikasi berbasis Android mampu menampilkan Objek Penari dalam bentuk 3 dimensi dengan posisi dan gerakan Tari Bali di atas marker dan berisi informasi tentang pergerakan Tari Bali melalui suara. Aplikasi bertujuan untuk mengenalkan Budaya Bali ke negara lain dan melestarikan Budaya Bali yang telah menjadi daya tarik tersendiri bagi wisatawan lokal maupun mancanegara [4]. Penelitian lainnya terkait pelestarian budaya yaitu penelitian oleh A A K Oka Sudana yang berjudul Optimization Algorithm in Traditional Card Game Rummy 21 pada Tahun 2016. Penelitian bertujuan untuk menghasilkan game dengan fitur Al (artificial intelligence) yang bisa berpikir seperti manusia dalam memecahkan masalah serta dapat melestarikan game tradisional Rummy 21 menggunakan teknologi mobile gaming [5].

Game Edukasi Perjalanan Dang Hyang Nirartha di Bali merupakan salah satu penelitian terkait media pembelajaran dan pelestarian budaya yang dikembangkan dari penelitian sebelumnya yaitu Membangun Game Edukasi Sejarah Walisongo, yang mengangkat kisah perjalanan Dang Hyang Nirartha. Game dikembangkan dengan Metode Accelerometer dan terdiri dari Fitur Gameplay, Fitur Informasi Pura dan Fitur Animasi. Fitur Gameplay dirancang dapat dimainkan dengan cara memiringkan smartphone ke atas, bawah, kiri dan kanan untuk menghindari musuh serta menyelesaikan permainan, yang terbagi menjadi 4 Scene Gameplay. Fitur Informasi Pura dirancang berisi sejarah Dang Hyang Nirartha secara berurutan dalam bentuk Peta Pulau Bali. Fitur Animasi dirancang dapat memberikan gambaran suasana perjalanan Dang Hyang Nirartha dalam bentuk animasi.

Penelitian dengan judul "Rancang Bangun Game Edukasi Perjalanan Dang Hyang Nirartha di Bali" dikembangkan menggunakan metode accelerometer. Accelerometer adalah metode yang berfungsi untuk menentukan derajat kemiringan dari smartphone dan digunakan untuk mengukur kecepatan suatu objek. Fungsi sensor accelerometer pada dasarnya untuk mengubah tampilan layar dari posisi landscape menjadi potrait ataupun sebaliknya, sehingga tampilan menu dan aplikasi yang ada pada smartphone menyesuaikan posisi dari smartphone [6].

\section{Metodologi}

Metodologi penelitian pada proses Rancang Bangun Game Edukasi Perjalanan Dang Hyang Nirartha di Bali menjelaskan mengenai tahapan atau prosedur penelitian dalam pembuatan game Perjalanan Dang Hyang Nirartha di Bali. Metodologi penelitian dari Rancang Bangun Game Edukasi Perjalanan Dang Hyang Nirartha di Bali yang dilakukan dalam penelitian yaitu pendefinisian permasalahan dan batasan masalah dari game yang dibuat, mengumpulkan dan mempelajari data yang digunakan sebagai landasan dalam perancangan dan pembuatan game melalui studi literatur, pembuatan gambar-gambar yang diperlukan dalam game, penentuan musik dan sound untuk latar game, pembuatan game, instalasi game yang telah selesai ke perangkat Android, pengujian terhadap game yang telah dibuat dan ter-install pada perangkat Android kemudian dilakukan analisis hasil pengujian game dan pengambilan kesimpulan. 


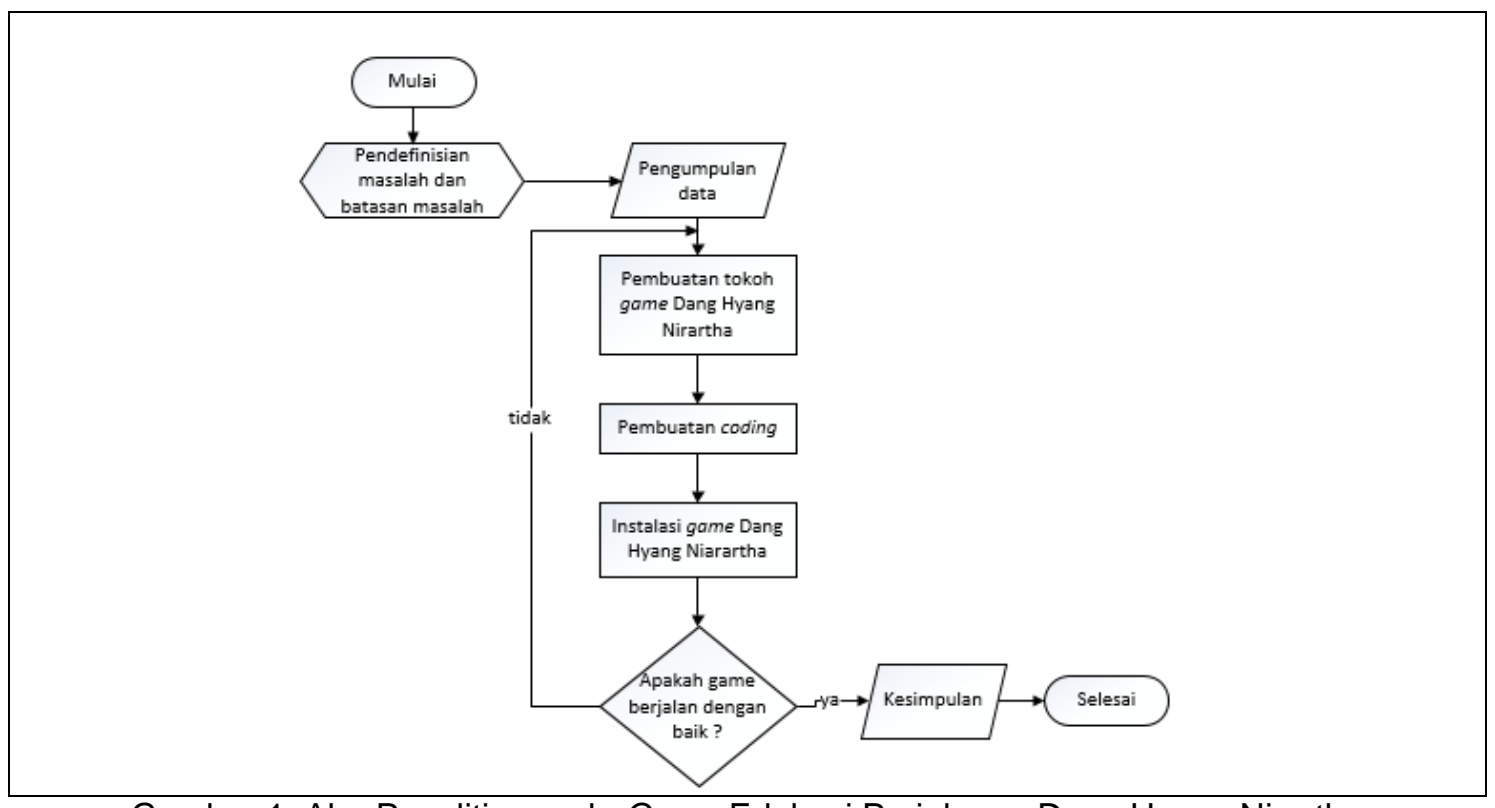

Gambar 1. Alur Penelitian pada Game Edukasi Perjalanan Dang Hyang Nirartha

Gambar 1 menunjukkan diagram alur penelitian Game Edukasi Perjalanan Dang Hyang Nirartha di Bali. Alur penelitian dimulai dari persiapan dalam menentukan tujuan dari penelitian yang dilakukan sampai mendapatkan simpulan dari hasil penelitian yang dilakukan.

\subsection{Diagram Use Case}

Diagram Use Case dari Rancang Bangun Game Edukasi Perjalanan Dang Hyang Nirartha di Bali dapat dilihat pada Gambar 2. Use case pada Gambar 2 menggambarkan interaksi antara pengguna dan Game Edukasi Perjalanan Dang Hyang Nirartha di Bali serta elemen use case dengan elemen use case lainnya. Pengguna dapat menggunakan use case yang dirancang yaitu menu mulai, galeri, opsi dan keluar sebagai sesuatu yang dapat dikerjakan. Pengguna dalam use case dapat memilih menu mulai yang merupakan layanan utama pada Game Edukasi Perjalanan Dang Hyang Nirartha di Bali. Gameplay mengenai perjalanan Dang Hyang Nirartha di Bali hanya dapat berjalan memanfaatkan sensor accelerometer pada device. Sensor Accelerometer merupakan sebuah sensor yang ada pada smartphone dan digunakan untuk menjalankan karakter pada gameplay yang terdapat pada Game Edukasi Perjalanan Dang Hyang Nirartha di Bali.

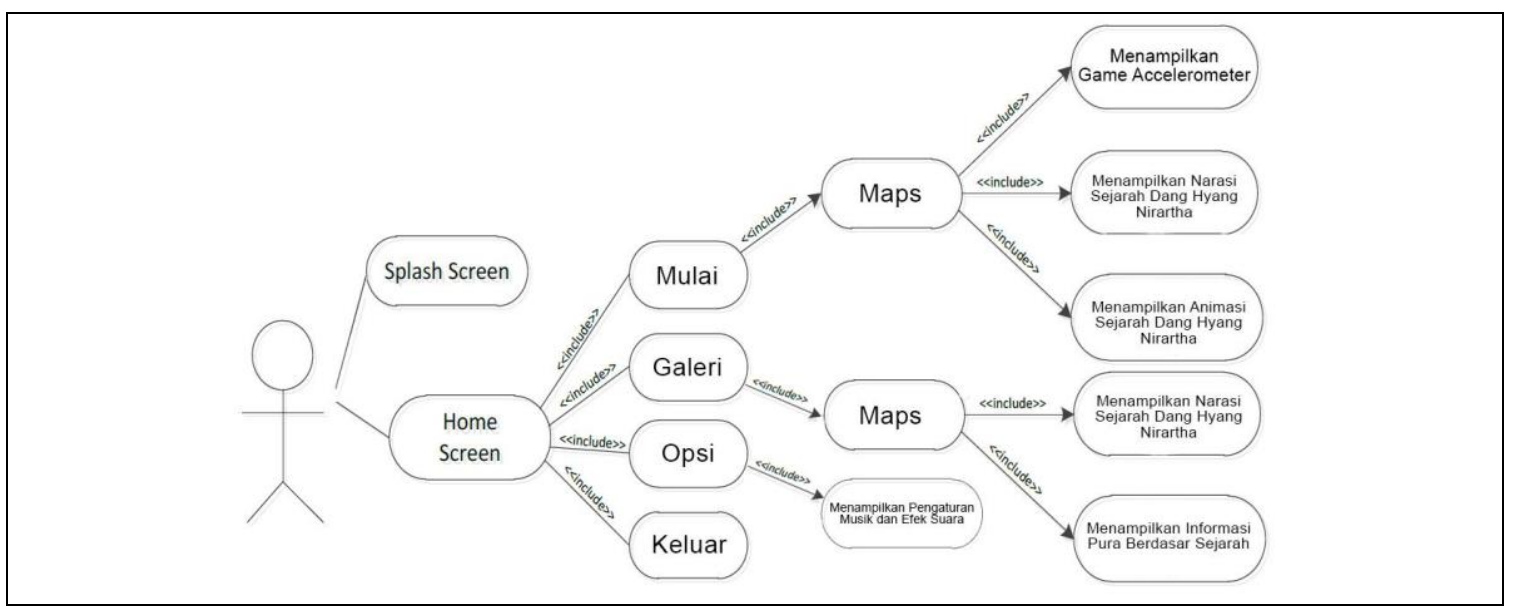

Gambar 2. Diagram Use Case 


\section{Kajian Pustaka}

Bab kajian pustaka berisi beberapa teori mengenai game dan teknologi yang merupakan teori pendukung yang menjadi dasar teori untuk pemecahan masalah dari penelitian yang dibuat.

\subsection{Sejarah Perjalanan Dang Hyang Nirartha di Bali}

Dang Hyang Nirartha awalnya merupakan seorang pendeta yang memberikan ajaran agama kepada umat Hindu di Pulau Jawa. Dang Hyang Nirartha meninggalkan Pulau Jawa bersama dengan keluarganya untuk menjadi kepala penasihat Raja Gelgel, Dalem Waturenggong di Pulau Bali [1]. Kejadian Dang Hyang Nirartha meninggalkan Pulau Jawa memicu keberangkatannya menuju Pulau Bali. Dang Hyang Nirartha dalam perjalanannya di Pulau Bali menyebarkan ajaran agama kepada penduduk di Pulau Bali, terutama cara menyembah Ida Sang Hyang Widhi dan Batara-Batari leluhurnya. Dang Hyang Nirartha merupakan pencipta arsitektur Padmasana untuk Pura Hindu di Bali. Pura dianggap sebagai penjelmaan dari Siwa yang agung di Pulau Bali. Pura yang dibangun karena ajaran beliau tersebar di seluruh Pulau Bali antara lain Pura Purancak, Pura Rambut Siwi dan Pura Amerta Sari di Jembrana, Pura Perapat Agung, Pura Pura Ponjok Batu dan Pura Bhatari Melanting di Buleleng, Pura Tanah Lot dan Pura Griya Kawitan Resi di Tabanan, Pura Taman Sari di Mangapuri (Mengwi), Pura Bukcabe, Pura Tugu, Pura Air Jeruk di Gianyar, Pura Puseh di Kamasan Gelgel, Pura Bukit Lingga di Desa Dawan, Pura Bhajing di Desa Bajing Klungkung, Pura Bukit Gong, Pura Gunung Payung di Jimbaran, Pura Sakenan di Pulau Serangan, serta Pura Kahyangan yang diberi nama Pura Uluwatu.

Dang Hyang Nirartha juga menciptakan sistem tiga pura untuk desa-desa di Bali yang disebut dengan Kahyangan Tiga. Pura untuk Dewa Brahma terletak di selatan desa, Pura untuk Dewa Wisnu terletak di utara desa dan Pura untuk Dewa Siwa terletak di tengah desa. Sistem tiga pura digunakan untuk memperkokoh konsep Trimurti dalam agama Hindu. Dang Hyang Nirartha juga memperkenalkan konsep Tirta (air suci) di Desa Gading Wani yang pada saat itu digunakan untuk mengobati masyarakat yang terkena penyakit dengan cara memercikkan air suci tersebut. Dang Hyang Nirartha dalam perjalanannya juga mengajarkan penduduk Desa Tuban cara membuat bubu (pukat) tanpa umpan agar banyak mendapat ikan dengan cara diam-diam. Dang Hyang Nirartha setelah sampai di Kerajaan Gelgel kemudian mensucikan (men-diksa) Dalem Waturenggong, memberi nasehat dan pelajaran kerohanian kepadanya, terlebih tata cara memerintah negara. Hari Selasa Kliwon Medangsia, Dang Hyang Nirartha mendapatkan wahyu dari Ida Sang Hyang Widhi Wasa bahwa Dang Hyang Nirartha pada hari itu dipanggil untuk meluhurkan diri (moksa). Dang Hyang Nirartha hanya menyisakan sebuah pustaka berisi ajaran ilmu kesaktian yang diserahkan kepada salah seorang putranya yang disimpan di Pura Luhur Uluwatu [1].

\subsection{Game Edukasi}

Game yang memiliki content pendidikan lebih dikenal dengan istilah game edukasi. Game berjenis edukasi bertujuan untuk memancing minat belajar anak terhadap materi pelajaran sambil bermain, sehingga dengan perasaan senang diharapkan siswa bisa lebih mudah memahami materi pelajaran yang disajikan. Jenis game edukasi sebenarnya lebih mengacu kepada isi dan tujuan game, bukan jenis yang sesungguhnya. Game edukasi merupakan hiburan yang dirancang untuk mengajarkan suatu topik/subyek atau membantu seseorang mempelajari keterampilan melalui apa yang dimainkan [7]. Contoh penelitian tentang game edukasi diantaranya penelitian yang dilakukan oleh Dewa Putu Andre Sanjaya berjudul Pengenalan Tradisi Budaya Bali melalui Aplikasi Game Explore Bali Berbasis Android [8], penelitian yang dilakukan oleh Sang Gde Aditya Bhaskara berjudul Permainan Edukasi Labirin Virtual Reality dengan Metode Collision Detection dan Stereoscopic [9], serta penelitian yang dilakukan oleh Made Gandhi Arsawiguna berjudul Rancang Bangun Aplikasi Game Tajen Berbasis Android menggunakan Artificial Intelligence [10].

\subsection{Sensor Accelerometer}

Sensor accelerometer adalah salah satu fitur yang ditanam pada smartphone Android, biasanya berfungsi untuk menentukan derajat kemiringan dari smartphone dan digunakan untuk mengukur kecepatan suatu objek. Fungsi sensor accelerometer pada dasarnya untuk 
mengubah tampilan layar dari posisi landscape menjadi potrait ataupun sebaliknya, sehingga tampilan menu dan aplikasi yang ada pada smartphone nantinya menyesuaikan posisi dari smartphone. Accelerometer juga berfungsi mengukur percepatan dinamis dan statis [6]. Pengukuran dinamis adalah pengukuran percepatan pada objek bergerak, sedangkan pengukuran statis adalah pengukuran terhadap gravitasi bumi. Salah satu contoh yang sering menggunakan sensor accelerometer adalah aplikasi game, misalnya game dalam balapan mobil sehingga dalam bermain cukup memiringkan smartphone saat belok ke kanan atau ke kiri.

\section{Hasil dan Pembahasan}

Bab Hasil dan Pembahasan berisikan hasil dari penelitian yang dilakukan berupa tampilan Game Edukasi Perjalanan Dang Hyang Nirartha di Bali.

\subsection{Tampilan Game Edukasi Perjalanan Dang Hyang Nirartha di Bali}

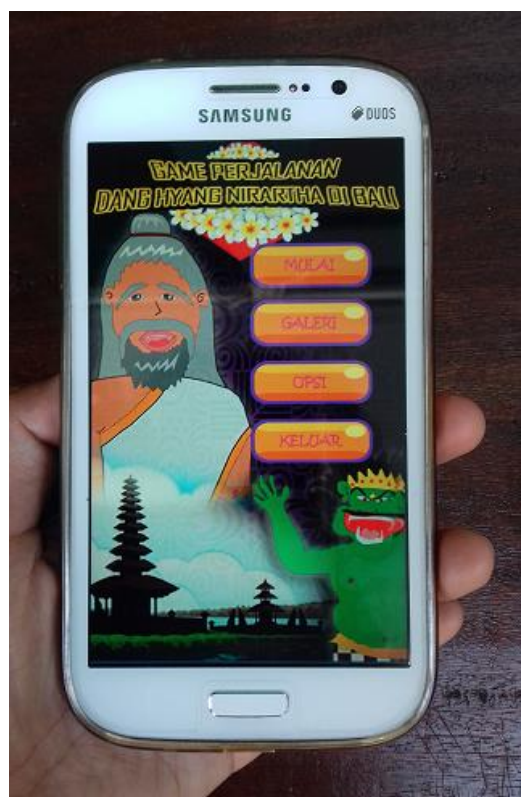

Gambar 3. Tampilan Scene Home Screen

Gambar 3 merupakan tampilan Scene Home Screen pada Game Edukasi Perjalanan Dang Hyang Nirartha di Bali. Scene Home Screen merupakan tampilan awal interface ketika game baru dibuka setelah sebelumnya muncul Scene Splash Screen. Scene Home Screen memiliki beberapa tombol yaitu Tombol Mulai, Tombol Galeri, Tombol Opsi dan Tombol Keluar. Pengguna dapat memulai penggunaan aplikasi game dengan memilih Tombol Mulai. Tombol Galeri digunakan untuk memberikan informasi Pura yang telah didirikan oleh Dang Hyang Nirartha di Bali. Tombol Opsi merupakan tombol untuk mengatur volume musik pada game. Tombol Keluar merupakan tombol yang digunakan untuk keluar dari Game Edukasi Perjalanan Dang Hyang Nirartha di Bali. 


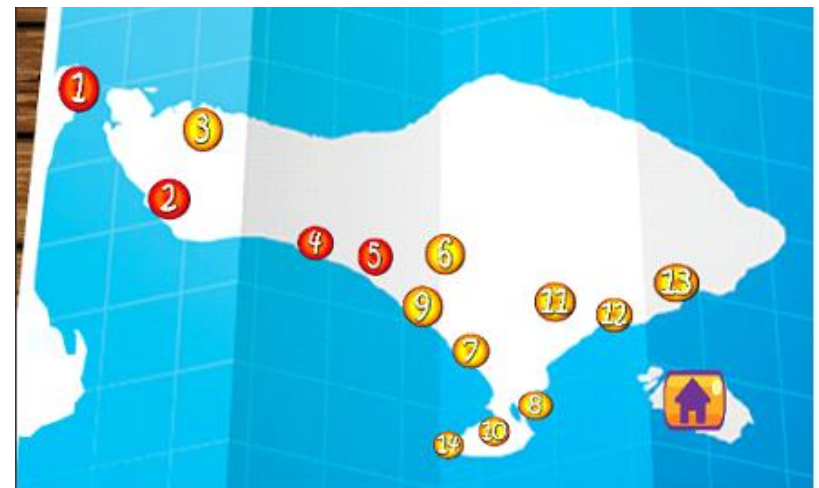

Gambar 4. Tampilan Scene Mulai

Gambar 4 merupakan tampilan Scene Mulai yang berisi gambar peta Pulau Bali dengan 14 stage game. Scene Mulai merupakan scene utama dari Game Edukasi Perjalanan Dang Hyang Nirartha di Bali dimana terdapat empat gameplay yang berbeda pada tombol stage berwarna merah. Gameplay pada Game Edukasi Perjalanan Dang Hyang Nirartha di Bali bekerja menggunakan sensor accelerometer yang ada pada smartphone.

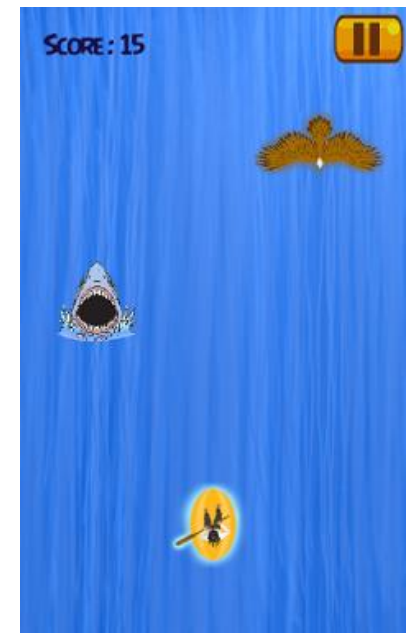

Gambar 5. Tampilan Scene Gameplay 1

Gambar 5 merupakan tampilan Scene Gameplay 1 yang ada pada Game Edukasi Perjalanan Dang Hyang Nirartha di Bali. Permainan dinyatakan kalah jika Objek Dang Hyang Nirartha mengenai rintangan ikan hiu, burung atau kayu. Dang Hyang Nirartha berhasil menyeberangi lautan menuju Pulau Bali jika skor yang didapatkan mencapai 100. 


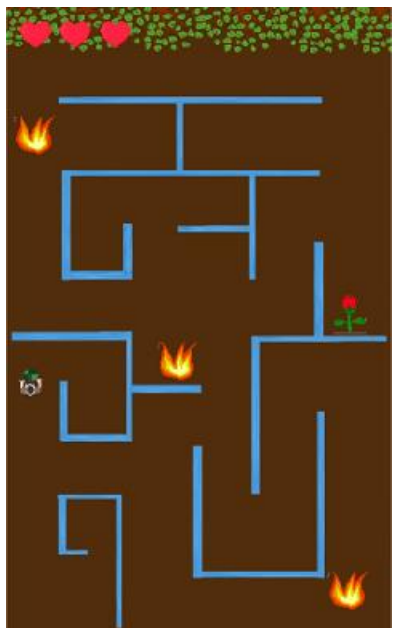

Gambar 6. Tampilan Scene Gameplay 2

Gambar 6 merupakan tampilan Scene Gameplay 2 pada Game Edukasi Perjalanan Dang Hyang Nirartha di Bali. Gameplay 2 memberikan 3 kali kesempatan (3 nyawa) untuk menang. Permainan berakhir dan dinyatakan kalah ketika Objek Warga mengenai musuh lebih dari 3 kali (nyawa habis). Kondisi kalah menampilkan pop-up atau panel kalah, sedangkan jika bunga teratai berhasil didapatkan sebelum nyawa habis maka muncul panel menang.

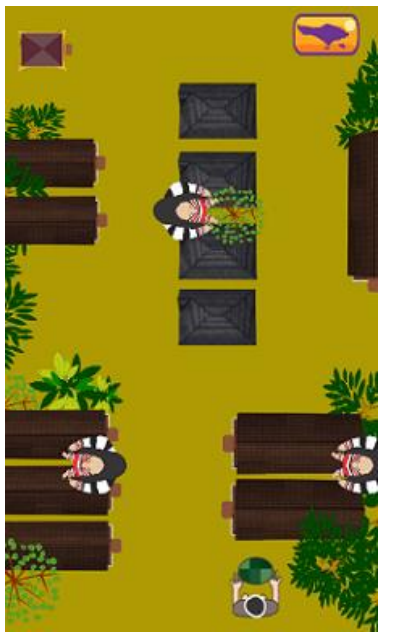

Gambar 7. Tampilan Scene Gameplay 3

Gambar 7 merupakan tampilan Scene Gameplay 3 pada Game Edukasi Perjalanan Dang Hyang Nirartha di Bali. Gameplay 3 menceritakan ketika Dang Hyang Nirartha memerintahkan warga Desa Gading Wani untuk menyebarkan ganten (kunyahan daun sirih) ke-4 penjuru desa. Pemain dinyatakan kalah jika Objek Ganten mengenai rintangan bhuta kala. 


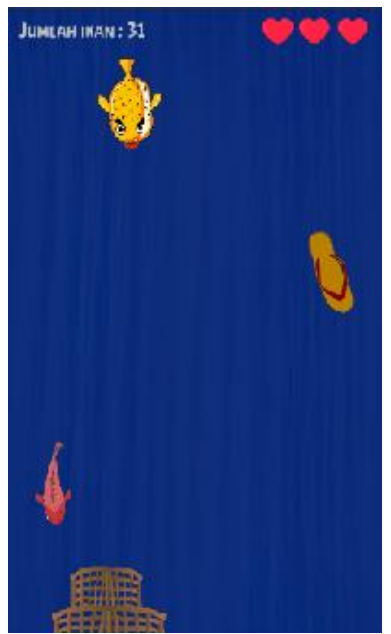

Gambar 8. Tampilan Scene Gameplay 4

Gambar 8 merupakan tampilan Scene Gameplay 4 pada Game Edukasi Perjalanan Dang Hyang Nirartha di Bali. Gameplay 4 menceritakan ketika Dang Hyang Nirartha mengajarkan warga Desa Tuban menangkap ikan menggunakan alat menangkap ikan terbuat dari bambu yang disebut bubu. Cara memainkan Gameplay 4 yaitu dengan mengarahkan bubu ke kiri dan ke kanan sampai ikan masuk ke dalam bubu. Gameplay 4 memanfaatkan sensor accelerometer dalam menggerakkan bubu.

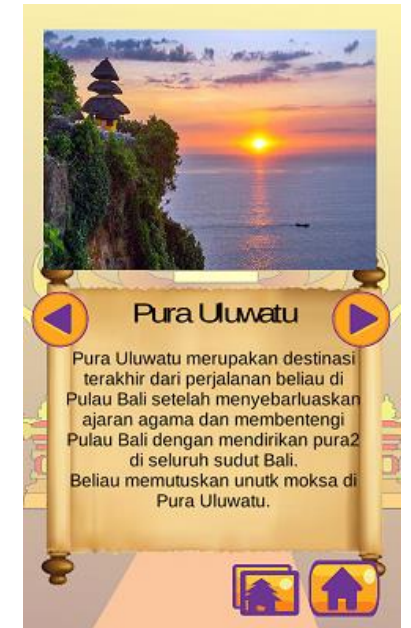

Gambar 9. Tampilan Scene Galeri

Gambar 9 merupakan tampilan Scene Galeri pada Game Edukasi Perjalanan Dang Hyang Nirartha di Bali. Scene Galeri merupakan scene yang menampilkan gambar dan informasi mengenai Pura yang berkaitan erat dengan perjalanan Dang Hyang Nirartha di Bali.

\subsection{Penilaian Kuesioner}

Bab penilaian kuesioner berisikan hasil dari penilaian berupa kuesioner yang telah dilakukan terhadap beberapa responden.

\subsubsection{Analisis Sistem Aplikasi}

Metode pengambilan data yang digunakan untuk melakukan pengujian pada Game Edukasi Perjalanan Dang Hyang Nirartha di Bali adalah menggunakan metode survei, dimana pengambilan data dilakukan menggunakan kuesioner sebagai media survei. Survei melibatkan 30 responden yang terdiri dari anak usia 8-11 tahun. 


\subsubsection{Aspek Pengalaman User}

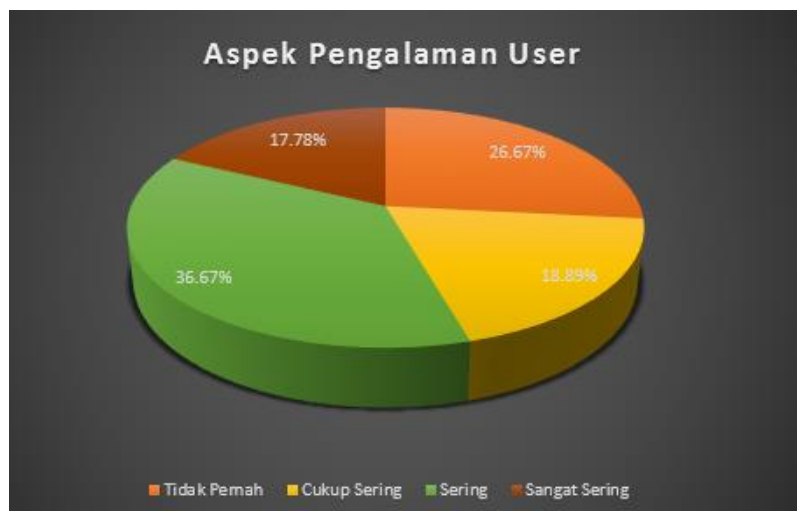

Gambar 10. Aspek Pengalaman User

Gambar 10 merupakan grafik Aspek Pengalaman User dari Game Edukasi Perjalanan Dang Hyang Nirartha di Bali. Penilaian pada Aspek Pengalaman User tergolong sering dengan persentase $36.67 \%$, tergolong tidak pernah dengan persentase $26.67 \%$, tergolong cukup sering dengan persentase $18.89 \%$ dan tergolong sangat sering dengan persentase $17.78 \%$. Berdasarkan persentase tersebut dapat disimpulkan bahwa $73.33 \%$ user pernah menggunakan gadget dan bermain game namun belum semua pernah memainkan game bertemakan sejarah.

\subsubsection{Aspek Multimedia}

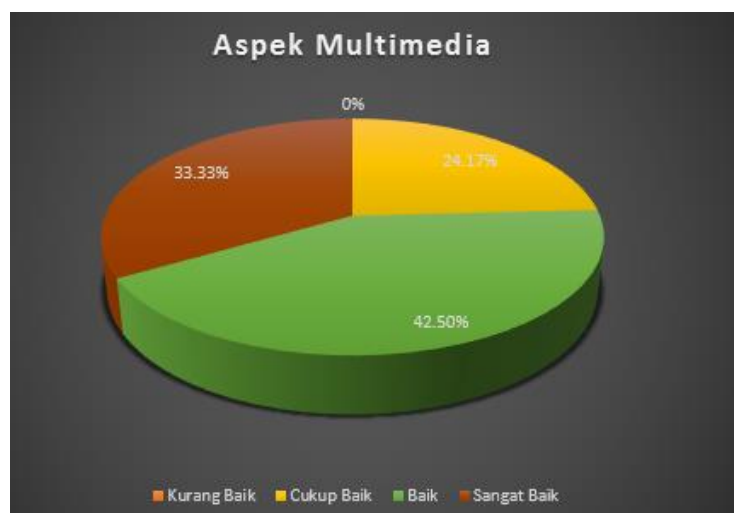

Gambar 11. Aspek Multimedia

Gambar 11 merupakan grafik Aspek Multimedia dari Game Edukasi Perjalanan Dang Hyang Nirartha di Bali. Penilaian pada Aspek Multimedia tergolong baik dengan persentase $42.5 \%$, tergolong sangat baik dengan persentase $33.33 \%$, tergolong cukup baik dengan persentase $24.17 \%$, dan tergolong kurang baik dengan persentase $0 \%$. Berdasarkan persentase tersebut dapat disimpulkan bahwa desain grafis serta user interface game sudah sangat baik. 


\subsubsection{Aspek Pengguna Aplikasi}

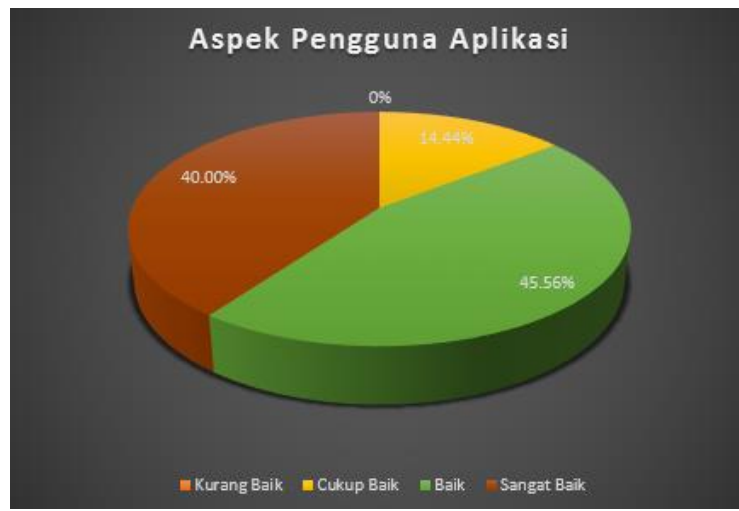

Gambar 12. Aspek Pengguna Aplikasi

Gambar 12 merupakan grafik Aspek Pengguna Aplikasi dari Game Edukasi Perjalanan Dang Hyang Nirartha di Bali. Penilaian pada Aspek Pemakai Aplikasi tergolong baik dengan persentase $45.56 \%$, tergolong sangat baik dengan persentase $40 \%$, tergolong cukup baik dengan persentase $14.44 \%$ dan tergolong kurang baik dengan persentase $0 \%$. Berdasarkan persentase yang diperoleh dapat disimpulkan bahwa game sangat mudah untuk digunakan oleh user dan user mendapatkan pemahaman tentang perjalanan tokoh Dang Hyang Nirartha di Bali.

\section{Simpulan}

Game yang dihasilkan mampu menyampaikan pembelajaran tentang perjalanan Dang Hyang Nirartha di Bali melalui informasi yang ditampilkan pada setiap stage dan gameplay yang menggambarkan kondisi perjalanan Dang Hyang Nirartha di Bali. Gameplay pertama mengangkat cerita Dang Hyang Nirartha yang menyeberangi laut Selat Bali menuju Pulau Bali yang dikemas dalam bentuk permainan menghindari burung dan ikan hiu. Gameplay kedua mengangkat cerita Dang Hyang Nirartha menuju ke timur, menghadapi naga dan memetik tiga bunga teratai berwarna merah, putih dan hitam yang berasal dari perut naga. Gameplay ketiga mengangkat cerita Dang Hyang Nirartha yang melenyapkan wabah penyakit di Desa Gading Wani, Desa Adat Lalanglinggah, Desa Surabrata, Kecamatan Selemadeg Barat, Kabupaten Tabanan. Gameplay keempat mengangkat cerita Dang Hyang Nirartha mengajari masyarakat desa untuk menangkap ikan menggunakan bubu yang dikemas dalam bentuk permainan menangkap ikan di laut. Seluruh gameplay dimainkan menggunakan sensor accelerometer yang ada pada smartphone. Game Edukasi Perjalanan Dang Hyang Nirartha di Bali juga menampilkan informasi mengenai tempat-tempat yang telah dilalui Dang Hyang Nirartha untuk menyampaikan cerita Dang Hyang Nirartha, selain gameplay yang ada. Game edukasi yang dihasilkan mampu menyampaikan pembelajaran terkait perjalanan Dang Hyang Nirartha yang ditunjukkan melalui hasil survei yang telah dilakukan yaitu Aspek Pengguna Aplikasi dengan persentase baik mencapai $45.56 \%$ dan nilai sangat baik dengan persentase $40 \%$. Hasil survei tersebut menunjukkan Game Edukasi Perjalanan Dang Hyang Nirartha merupakan media hiburan yang menyenangkan dan mampu memberikan pemahaman tentang perjalanan Dang Hyang Nirartha di Bali.

\section{Daftar Pustaka}

[1] I. B. Sidemen, I. B. Rai Putra, I. B. Dharmika, and A. A. G. Alit Geria, Kusumanjali Persembahan kepada Dang Hyang Nirartha, I. Denpasar: Yayasan Dharmopadesa, 2000.

[2] N. I. Widiastuti and I. Setiawan, "Membangun Game Edukasi Sejarah Walisongo," Jurnal IImiah Komputer dan Informasi, vol. 1, no. 2, pp. 41-48, 2012.

[3] I. D. M. Y. A. Putra, A. A. K. A. C. Wiranatha, and P. W. Buana, "Rancang Bangun Game Tapel Bali pada Platform Android," Lontar Komputer, vol. 6, no. 1, pp. 1-12, 2015.

[4] N. P. S. Franza, A. A. K. O. Sudana, and K. S. Wibawa, "Application of Basic Balinese Dance Using Augmented Reality on Android," Journal of Theoretical and Applied Information Technology, vol. 90, no. 1, pp. 61-66, 2016. 
[5] A. A. K. O. Sudana, I. G. K. P. Aditya, and I. P. A. E. Pratama, "Optimization Algorithm in Traditional Card Game Rummy 21," International Journal of Computer Applications, vol. 146, no. 8, pp. 41-47, 2016.

[6] M. Liu, "A Study of Mobile Sensing using Smartphones," International Journal of Distributed Sensor Networks, vol. 9, no. 3, pp. 1-11, 2013.

[7] A. G. A. Prayoga, I. P. A. B. Bayupati, and A. A. K. A. C. Wiranatha, "Game Edukasi Mengenal Huruf Katakana dan Hiragana Berbasis Android," Lontar Komputer, vol. 6, no. 3, pp. 150-161, 2015.

[8] D. P. A. Sanjaya, I. K. A. Purnawan, and N. K. D. Rusjayanthi, "Pengenalan Tradisi Budaya Bali Melalui Aplikasi Game Explore Bali Berbasis Android," Lontar Komputer, vol. 7, no. 3, pp. 163-174, 2016.

[9] S. G. A. Bhaskara, P. W. Buana, and I. K. A. Purnawan, "Permainan Edukasi Labirin Virtual Reality dengan Metode Collision Detection dan Stereoscopic," Lontar Komputer, vol. 8, no. 2, pp. 65-76, 2017.

[10] M. G. Arsawiguna, A. A. K. A. C. Wiranatha, and K. S. Wibawa, "Rancang Bangun Aplikasi Game Tajen Berbasis Android menggunakan Artificial Intelligence," Lontar Komputer, vol. 6, no. 2, pp. 84-95, 2015. 